\title{
Role of the NFKB-signaling pathway in cancer
}

This article was published in the following Dove Press journal:

OncoTargets and Therapy

\section{Longzheng Xia ${ }^{1, *}$ \\ Shiming $\operatorname{Tan}^{1, *}$ \\ Yujuan Zhou' \\ Jingguan Lin' \\ Heran Wang' \\ Linda Oyang' \\ Yutong Tian' \\ Lu Liu' \\ Min Su' \\ Hui Wang' \\ Deliang Cao ${ }^{1,2}$ \\ Qianjin Liao'}

'Hunan Key Laboratory of

Translational Radiation Oncology,

Hunan Cancer Hospital and Affiliated

Cancer Hospital of Xiangya School

of Medicine, Changsha, Hunan, China;

${ }^{2}$ Department of Medical Microbiology, Immunology, and Cell Biology,

Simmons Cancer Institute, Southern

Illinois University School of Medicine,

Springfield, IL, USA

*These authors contributed equally to this work
Correspondence: Qianjin Liao;

Deliang Cao

Hunan Key Laboratory of Translational

Radiation Oncology, Hunan Cancer

Hospital and Affiliated Cancer Hospital

of Xiangya School of Medicine, Central

South University, 283 Tongzipo Road,

Changsha, Hunan 410013, China

Tel +8673 I 8865 I68I

Fax $+8673 \mid 88651999$

Email march-on@126.com;

dcao@siumed.edu

\begin{abstract}
Cancer is a group of cells that malignantly grow and proliferate uncontrollably. At present, treatment modes for cancer mainly comprise surgery, chemotherapy, radiotherapy, molecularly targeted therapy, gene therapy, and immunotherapy. However, the curative effects of these treatments have been limited thus far by specific characteristics of tumors. Abnormal activation of signaling pathways is involved in tumor pathogenesis and plays critical roles in growth, progression, and relapse of cancers. Targeted therapies against effectors in oncogenic signaling have improved the outcomes of cancer patients. NF $\kappa B$ is an important signaling pathway involved in pathogenesis and treatment of cancers. Excessive activation of the NFKBsignaling pathway has been documented in various tumor tissues, and studies on this signaling pathway for targeted cancer therapy have become a hot topic. In this review, we update current understanding of the NFKB-signaling pathway in cancer.
\end{abstract}

Keywords: nuclear factor kappa-B, p65, signaling pathway, cancer, inflammation

\section{Introduction}

Malignant tumors have become one of the most deadly diseases and a prominent public health problem threatening human lives around the world. ${ }^{1}$ In recent years, with social and economic development, as well as aging of the population, the incidence and mortality of cancer are increasing. ${ }^{2}$ The overall incidence of common malignant tumors will rise from 14 million in 2012 to a predicted 19 million in 2025 and 24 million in 2035, according to the World Health Organization. ${ }^{3,4}$ Cancer occurs due to oncogene activation, tumor-suppressor gene inactivation, loss of control of the cell cycle, genomic instability, telomerase loss, and resistance of apoptosis. ${ }^{5}$ However, the specific pathogenesis of cancer varies with types of cancers.

The cell-signaling pathway is the process by which cell responds to stimuli of extracellular signaling molecules that bind to receptors located on the cell membrane or in the cytoplasm of cells. This binding to receptors transfers signals to the nucleus and induces corresponding gene expression, thus producing biological effects and cellular responses. ${ }^{6}$ In tumorigenesis, signaling pathways are less controlled..$^{7,8}$ Abnormal regulation and cross-talk of cell-signal-transduction pathways play a key role in cancer, and obstruction of or anomalies in signaling pathways may lead to excessive cell proliferation, apoptotic resistance, angiogenesis, invasion, and metastasis, leading to development and progression of cancer. ${ }^{5} \mathrm{NF} \kappa \mathrm{B}$ is an important signaling pathway that is involved extensively in cancer development and progression. Through controlling the expression of target genes, such as TNFA, IL6, $B C L X L, B C L 2, B C L X S, X I A P$, and $V E G F$, NFKB mediates tumor-cell proliferation, survival, and angiogenesis. ${ }^{9}$ This review focuses on this NFKB-signaling pathway in tumors. 


\section{Overview of NFkB-signaling pathways}

\section{Proteins and structure of NFKB family}

$\mathrm{NF} \kappa \mathrm{B}$ is an important transcription-factor family of five subunits: Rel (cRel), p65 (RelA, NFkB3), RelB, p105/p50 (NFkB1), and p100/p52 (NFkB2). ${ }^{10-12}$ Among these, p65, cRel, and RelB contain an N-terminal Rel-homologous domain (RHD; about 300 amino acids) and a C-terminal transactivation domain (TAD; Figure 1), ${ }^{13,14}$ while p50 and p52 have only an RHD, but not a TAD. ${ }^{15,16}$ The C-terminal of p100 and p105 contains ankyrin repeats that function as a p52 and p50 inhibitor. The RHD is responsible for DNA binding and dimerization between different or identical family members, including the nuclear localization sequence and IKB-binding region, leading to homomeric or heteromeric binding of the subunits. ${ }^{17}$ The TAD is associated only with transcriptional activation. ${ }^{18}$ Therefore, the p50-p52 homologous dimer does not activate gene transcription, but acts as an inhibitory molecule. Both p50 and p52 are usually present in cells in the form of their precursors. ${ }^{19}$ In these members, RelB can form dimers only with $\mathrm{p} 50$ or $\mathrm{p} 52$, but others can form either homologous or heterologous dimers. However, the most common NFKB dimer is the heterodimer of p65-p50. These homologous and/or heterologous dimers can bind to a specific sequence (ie, NFKB sites) of the target gene to regulate gene transcription. Therefore, NF $\mathrm{KB}$ regulates the activity of cells through the slight difference in binding of these NFKB dimers to targeted sequences.

\section{$\mathrm{IKBs}$ and IKKs}

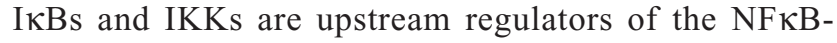
signaling pathway. In cells that are not stimulated, NFKB dimers are present in an inactive state by binding to three inhibitory factors ( $(\kappa \mathrm{B} \alpha, \mathrm{I} \kappa \mathrm{B} \beta$, and $\mathrm{I} \kappa \mathrm{B} \varepsilon$ ) of the $\mathrm{NF} \kappa \mathrm{B}$ in the cytoplasm, which blocks the nuclear localization sequence and prevents the NFKB from transition into the nucleus. ${ }^{20,21}$

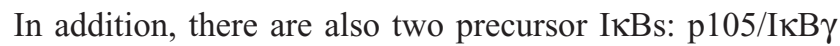
and $\mathrm{p} 100 / \mathrm{I} \kappa \mathrm{B} \delta .^{22} \mathrm{I} \kappa \mathrm{B} \alpha$ specifically inhibits the p50/RelA

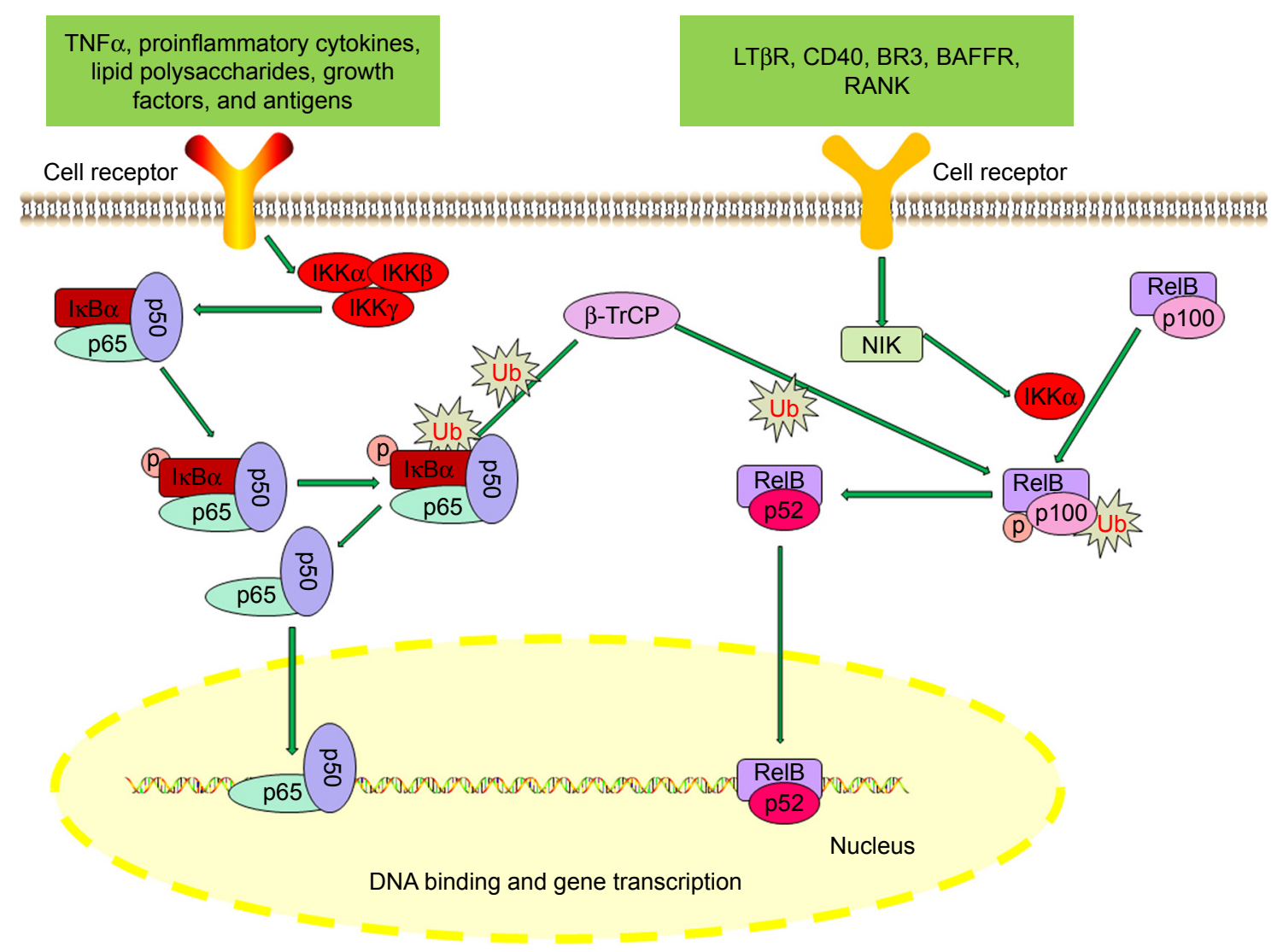

Figure I Structure of NFKB members.

Notes: The NFKB family consists of three proteins with a transactivation domain (RelA [p65], cRel, and RelB) and two proteins lacking a transactivation domain ( $\mathrm{pl05/p50}$ and p 100/p52). Similarly, only p /05/p50 and pl00/p52 have ankyrin repeats that function as p52 and p50 inhibitors. However, all these proteins share an Rel-homology domain, associated with DNA binding, dimerization, nuclear localization and IKB binding, and nuclear localization signal exposure, which is vital to the translocation of the dimer into the nucleus.

Abbreviation: NIK, NFKB-inducing kinase. 
heterodimer, I $\kappa \mathrm{B} \beta$ targets the RelA/cRel heterodimer ${ }^{23}$ and I $\kappa \varepsilon \varepsilon$ inhibits the RelA and cRel dimers. ${ }^{24}$ Although different external stimuli cause differential activation of $\mathrm{NF} \kappa \mathrm{B}$ through different I $\mathrm{KBs},{ }^{25}$ almost all known NF $\kappa \mathrm{B}$ agonists can rapidly and transiently activate NF $\kappa B$ by degradation of I $\mathrm{I} B{ }^{26}$ The I $\mathrm{I} B$ proteins $\mathrm{p} 105 / \mathrm{I} \kappa \mathrm{B} \gamma$ and $\mathrm{p} 100 / \mathrm{I} \kappa \mathrm{B} \delta$ play a dual role, ie, precursors of the NFKB proteins $\mathrm{p} 50$ and $\mathrm{p} 52$ and inhibitors of NFKB signaling. ${ }^{27}$ Different external stimuli have differential effects on the different subunits of I $\kappa$ Bs, leading to differential activation of the NFKB pathway.

The IKK (IкB kinase) complex consists of the catalytic subunits IKK $\alpha$ and IKK $\beta$ and the regulatory subunit NFKB essential modifier (NEMO; also called IKK $\gamma$ ) ${ }^{20}$ The IKKs are upstream regulators of IKBs. ${ }^{28}$ Both IKK $\alpha$ and IKK $\beta$ subunits have about $52 \%$ of the sequence identity, but play a key but divergent role in regulation of global NFкBsignaling activity. ${ }^{29}$ NEMO contains several domains that are crucial for its function as a regulatory subunit of the canonical IKK complex. The N-terminal coiled-coil domain of NEMO interacts with IKK $\alpha$ and IKK $\beta .^{30}$ Different IKKs demonstrate differential strength and speed for different substrates. IKK $\alpha$ is mainly the specific upstream kinase of I $\kappa B \beta$ and can strongly phosphorylate the Ser 23 of I $\mathrm{I} B \beta$, but not the Ser19. This inequivalent phosphorylation of Ser23

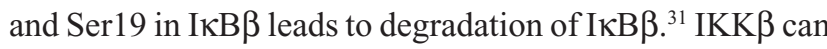
specifically phosphorylate the Ser sites of I $\mathrm{I} B \alpha$ and $\mathrm{I} \kappa \mathrm{B} \beta$, and the intensity is 20 times that of IKK $\alpha$. In addition, the

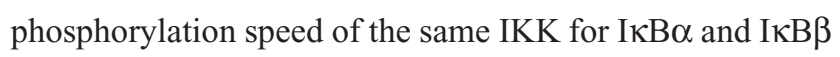
are different. IKK $\beta$ has stronger affinity for I $\mathrm{I} B \alpha$ than IKB $\beta$.

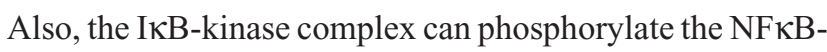
bound IKB protein and contribute to proteasomal degradation of the IKB protein faster. ${ }^{32}$

\section{Activation of NFKB-signaling pathway}

In a resting status of cells, complexes formed from $\mathrm{NF \kappa B}$

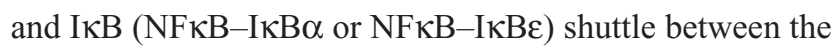
cytoplasm and nucleus in a dynamic equilibrium. ${ }^{33}$ When cells are stimulated by extracellular signals, such as TNF $\alpha$, IL1, lipopolysaccharide, viral double-stranded RNA, and ionizing radiation, $\mathrm{NF \kappa B}$ is activated and enters the nucleus to bind to target genes. ${ }^{34-39}$ Upon activation, $\mathrm{NF \kappa B}$-signaling pathways are classified as canonical or noncanonical (Figure 2). ${ }^{40}$ The common regulatory step in both pathways is activation of the IKK complex. The IKK complex is phosphorylated, and in turn induces phosphorylation of $\mathrm{I} \kappa \mathrm{B}$ proteins $\mathrm{I} \kappa \mathrm{B} \alpha$ or $\mathrm{I} \kappa \mathrm{B} \beta$, leading to ubiquitination and degradation by proteasomes. Similarly, p100 and p105 are phosphorylated and cleaved into maturated p52 and p50 upon IKK activation. Therefore, $\mathrm{NF \kappa B}$ dimers are released from their inhibitors and free to translocate into the nucleus to regulate expression of their target genes.

The canonical NFKB-transcription factor is an inactive dimer composed of a p50 and RelA/p65 subunit, which largely resides in the cytoplasm as part of a latent complex

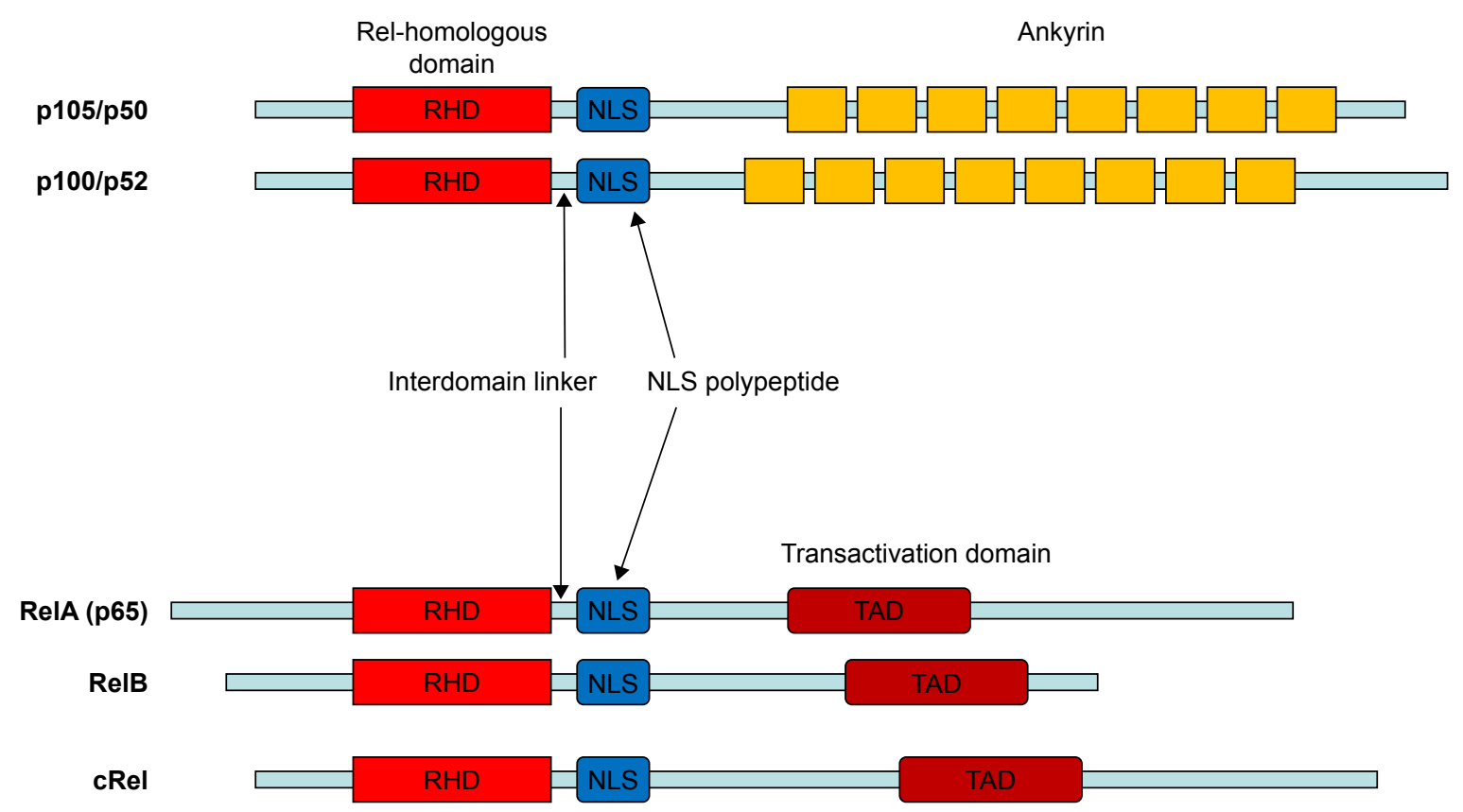

Figure 2 Activation of NFKB cascade by the classical/canonical signaling pathway (right) and alternative/noncanonical signaling pathway (left). Abbreviations: NLS, nuclear localization sequence; RHD, Rel-homologous domain; TAD, transactivation domain. 
with I $\mathrm{kB} \alpha$ under basal conditions. ${ }^{41,42}$ The formation of $\mathrm{p} 65$ (RelA)-p50 or p65-cRel heterodimers is a key to activation. ${ }^{43}$ Stimulation by proinflammatory cytokines, such as TNF $\alpha$, IL1 $\beta$, TLR ligands, and T-cell-receptor activators, results in activation of the IKK $\beta$ complex, and then I $\mathrm{KB} \alpha$ is phosphorylated at Ser32 and Ser36 by the IKK complex, ${ }^{44,45}$ polyubiquitinated at K63, and degraded by proteasomes. ${ }^{46-49}$ Degradation of $\mathrm{I} \kappa \mathrm{B} \alpha$ consequently releases the canonical $\mathrm{NF} \kappa \mathrm{B}$ dimer p50-RelA/p65 to translocate into the nucleus and activate gene transcription. ${ }^{50}$

Although the canonical NFKB pathway has been more extensively studied, it is not to be ignored that the noncanonical pathway (or alternative NFKB pathway) is vital in some aspects. ${ }^{51}$ This alternative pathway is activated by TNFreceptor (TNFR) family members, such as LT $\beta R$, BAFFR, RANK, and CD40. ${ }^{52-56}$ Once the receptor is activated, TRAF proteins are able to mediate the activity of NFKB-inducing kinase and activate an IKK $\alpha$ homodimer at the same time, ${ }^{57,58}$ ultimately leading to heterodimerization of the $\mathrm{p} 100$ precursor with RelB and processing into the active p52 subunit. ${ }^{59}$ This processing of p100 induces the generation of the noncanonical transcription factor, a p52-RelB dimer, which then binds to $\kappa \mathrm{B}$ DNA-binding sites and controls expression of targeted genes. ${ }^{59}$ Therefore, activation of these two pathways is achieved by phosphorylation of I $\kappa \mathrm{B}$ proteins, which relieve the inhibition of I $\kappa \mathrm{B}$ proteins to NF $\kappa \mathrm{B}$ dimers. ${ }^{60}$

\section{Posttranslational modifications of NFKB proteins}

$\mathrm{NF} \kappa \mathrm{B}$ has hundreds of validated transcriptional targets, ${ }^{61}$ and thus NFאB-signaling activity is under stringent spatial and temporal control at the levels of nuclear translocation and posttranslational modifications (PTMs) of signaling components. ${ }^{61,62}$ There is a wide range of PTMs of NFאB subunits, ${ }^{63}$ and PTMs provide essential mechanisms differentially to regulate $\mathrm{NF} \kappa \mathrm{B}$-signaling activity in response to the various stimuli that activate this pathway in many cancer cells. ${ }^{64,65}$ Although these modifications have a critical role in the normal and pathological functions of $\mathrm{NF} \kappa \mathrm{B}$ in vivo, the physiological significance of PTMs remains unclear in cancer cells. ${ }^{66}$ PTMs not only can contribute to the control of nuclear translocation but also have an important influence in functions of NFKB subunits, including protein degradation, DNA binding, and transcriptional activity. ${ }^{67-69}$ PTMs of $\mathrm{NF \kappa B}$ include phosphorylation, ubiquitination, acetylation, and methylation. ${ }^{70}$ Herein, we focus on the ubiquitination, phosphorylation, and methylation of the functional subunits of NFKB.
Ubiquitination, a PTM of addition of ubiquitin (Ub) moieties to a protein, is the primary mechanism of protein turnover in the cell, and is recognized as the "traditional" function of $\mathrm{Ub}$ tagging. ${ }^{71} \mathrm{Ub}$ moieties on NFKB-signaling proteins can serve as a docking platform for other proteins with specific Ub-binding domains. ${ }^{72}$ First, the Ub moiety is activated by the E1 Ub-activating enzyme. Following activation, one of several E2 Ub-conjugating enzymes transfers Ub from E1 to several E3 enzymes (Ub ligases), to which the substrate protein is specifically bound. The Ub moiety includes seven lysine (K) residues (K6, K11, K27, K29, K33, $\mathrm{K} 48$, and K63) and a methionine at the N-terminus (M1), which can link another $\mathrm{Ub}$ to form a polyUb chain. ${ }^{73}$

$\mathrm{Ub}$ signaling controls activation of $\mathrm{NF} \kappa \mathrm{B}$ and innate immunoresponses downstream of pattern-recognition receptors, such as Toll-like receptors, nucleotide-oligomerization domain-like receptors, and cytokine receptors, eg, TNFR1, in normal intestinal epithelial cells and colon cancer cells. ${ }^{74-76}$ K48-linked polyubiquitination is a key step in releasing $\mathrm{NF} \kappa \mathrm{B}$ from I $\kappa \mathrm{Bs}$ in the canonical pathway and processing of $\mathrm{p} 100 / 102$ into $\mathrm{p} 52 / 50$ in the noncanonical pathway to activate the NFкB pathway in inflammatory diseases, autoimmune diseases, and cancers. ${ }^{70,77,78}$ The Skp1-Cullin-F-box (SCF)$\beta \mathrm{TrCP}$ complex catalyzes the K48-linked polyubiquitination of $\mathrm{I} \kappa \mathrm{B} \alpha$ at two N-terminal lysine residues (K21 and K22), inducing $26 \mathrm{~S}$ proteasome-dependent degradation of $\mathrm{I} \kappa \mathrm{B} \alpha$ and nuclear translocation of canonical NF $\kappa B$. In addition, the phosphorylation of $\mathrm{I} \kappa \mathrm{B} \alpha$ induced by NF $\kappa \mathrm{B}$-inducing kinase could cause the phosphorylation of p100 on the C-terminal region (Ser866 and Ser870) and polyubiquitination of p100 by the $\mathrm{SCF}-\beta \mathrm{TrCP}-\mathrm{E} 3$ ligase complex to regulate the activity of the noncanonical NFKB. ${ }^{70}$ The IKK $\beta$ subunit is also polyubiquitinated by a K63-linked chain in human cervical HeLa cells. ${ }^{79}$ Importantly, activation of IKK is essential to productive signaling and NF $\mathrm{NB}$-mediated transcription, and its activation depends on the binding of Met1-Ub by the IKK subunit NEMO. ${ }^{80}$

Phosphorylation is critical for NFאB activity, including binding to and transcription of genes that contain a consensus sequence. ${ }^{81}$ Phosphorylation of key NFKB-signaling molecules often positively mediates signal transduction by inducing protein conformational changes in breast cancer cell lines. ${ }^{82,83}$ Activation of NFKB signaling is involved in a series of phosphorylation events of upstream NFKB regula-

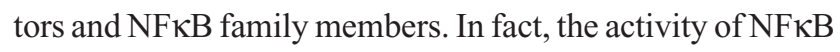
is controlled to a great extent by phosphorylation of RelA or upstream regulators in esophageal squamous-cell carcinoma, gastric cancer, and oral cancer. ${ }^{81,84}$ The main subunit RelA of 
NFкB is targeted for phosphorylation at many phosphoacceptor sites within both the RHD (Ser205, Ser276, Ser281, Ser311, and Thr254) and TAD (Ser468, Ser529, Ser535, Ser536, Thr435, and Thr505). ${ }^{81}$ For example, the phosphorylation of Ser536 induced in the cytoplasm can increase NF $\kappa$ B transcriptional activity, while phosphorylation of Ser529 increases DNA binding and oligomerization in laryngeal cancer cells. The phosphorylation of Ser536 results in nuclear accumulation of RelA through disruption of the cytoplasmic/nuclear shuttling of NF $\kappa \mathrm{B}-\mathrm{I} \kappa \mathrm{B} \alpha$ complexes. In addition, phosphorylation of Ser276 can promote RelA interaction with the transcriptional coactivator $\mathrm{CBP} /$ p300. ${ }^{85}$ Meanwhile, p-Ser276 RelA facilitates recruitment of DNMT1/DNA (cytosine 5)-methyltransferase 1 to chromatin and subsequent BRMS1-promoter methylation and transcriptional repression in human NSCLC cells. ${ }^{86}$ In addition, phosphorylation of I $\mathrm{KBs}$ is a key step of their proteasomal degradation and the release of $\mathrm{NF} \kappa \mathrm{B}$ for nuclear translocation and activation of gene transcription. Cytokines in the tumor microenvironment, such as TNF $\alpha$, could bind to the cellsurface TNF receptor, causing TNF-receptor multimerization and interacting with TRADD in the cytoplasm. ${ }^{87,88}$ TRADD recruits TRAF $^{89}$ and kinase RIP. ${ }^{90}$ Then, the stimulated signals are transmitted to IKK by RIP, which can make the Ser32 and Ser36 residues in $\alpha$-subunits of I $\mathrm{B}$ and Ser19 and Ser23 residues in $\beta$-subunits of I $\kappa$ B phosphorylated. ${ }^{91,92}$ Then, I $\mathrm{KB}$ protein is dissociated from the $\mathrm{p} 50-\mathrm{p} 65-\mathrm{I} \kappa \mathrm{B}$ trimer and subsequently degraded by proteasomes, activating the NFкB pathway. ${ }^{77}$

In recent years, accumulated evidence has suggested that histone-modifying enzymes not only modify histone proteins but also play a role in the modification of nonhistone proteins, such as NFkB. ${ }^{93} \mathrm{NF} \kappa \mathrm{B}$ can be methylated reversibly on lysine or arginine residues by histone-modifying enzymes, including lysine and arginine methyl transferases and demethylases. The methylations of both lysine and arginine occur mainly on the p65 subunit of NFкB. ${ }^{94,95}$ The methylated K sites include $\mathrm{K} 37, \mathrm{~K} 218, \mathrm{~K} 221$, K310, K314, and $\mathrm{K} 315$ that are modified by different histone-modifying enzymes. ${ }^{96}$ Among the histone methyl transferases, SET9, SETD6, and NSD1 are capable of activating NFKB by methylating K218 and K221 of $\mathrm{p} 65$, which provides a potential mechanism for how NSD1 might contribute to tumor formation, as constitutive activation of NFKB is a hallmark of many cancers. Methylation of NFKB can profoundly affect the functions of NFKB by altering its stability, transactivation potency, and affinity to DNA, and thus affect the strength and duration of inducible gene expression. Meanwhile, the differential methylation of K37 and K218/221 on NFKB is able to constitute "bar codes" that guide differential activation of $\mathrm{NF \kappa B}$, binding to specific promoters. ${ }^{96}$

\section{Roles of NFKB in cancer}

At present, the role of the NFKB-signaling pathway in cell biogenic activities is the hot spot of cancer research. NF $\kappa B$ signaling is involved in cellular immunity, inflammation, and stress, as well as regulation of cell differentiation, proliferation, and apoptosis. ${ }^{97-101}$ The NFKB pathway is often altered in both solid and hematopoietic malignancies, promoting tumor-cell proliferation and survival..$^{52,102,103}$ However, recent evidence indicates that NFאB plays a tumor-suppressive role in certain cancers through transcriptional activation of the Fas ligand. ${ }^{104}$

\section{Pro- and anti-inflammatory effects of NFKB}

The pathogenic role of inflammation in cancer has drawn intensive research and highlighted the context-dependent modulation of inflammation-associated cancer by the transcription factor NFKB. ${ }^{105}$ Through control of inflammatory responses, NFKB has influence in tumor development and progression by excessive innate immunity activation and abnormal cell growth. ${ }^{106}$ Inflammation-associated cancer can secrete various cytokines and chemokines through NFאB binding to the promoters of genes, such as $I L 1 B, T N F$, and IL6. ${ }^{107}$ At the same time, activation of NFKB can be regulated by the TNF $\alpha$-receptor family, including RANKL. ${ }^{108,109}$

It is well known that inflammatory gene signatures are altered in various tumor-cell lines and specimens of different histological and molecular subtypes. Researchers have found that the inflammatory genes, such as IL1, IL6, IL8, and CCL2, are also actively expressed in glioma-cell lines, playing differential and cooperative roles in promoting proliferation, invasion, angiogenesis, and macrophage polarization in vitro. ${ }^{110}$ Interestingly, the NFאB signaling activated by TNF can also induce proinflammatory chemokines, such as CCL20, CXCL13, and CXCL8, that are specific ligands for the chemokine receptor CXCR2 in ovarian cancer cells. ${ }^{11,112}$ It is a positive-feedback loop that high expression of proinflammatory genes in the tumor microenvironment can be increased through activation of canonical and noncanonical NF $\kappa B$ pathways to accelerate the development of tumors and also promote the expression of proinflammatory proteins through binding of specific dimers of activated NFKB to promoters of proinflammatory genes. For example, IL1 can induce the phosphorylation of MKK4, which is indispensable 
in the processing of $\mathrm{NF} \kappa \mathrm{B}$ p100 to the p52-active form and translocation of $\mathrm{p} 52$ from the cytoplasm to the nucleus. ${ }^{10,113}$ Besides the proinflammatory function, NF $\kappa B$ has a direct antiinflammatory effect. NFKB can inhibit the formation of inflammasomes through inhibition of inflammasome-dependent caspase 1 activation, but the mechanism is not entirely clear and is probably related to NFKB-induced expression of antiapoptotic proteins, such as PAI2 and Bcl-xL. ${ }^{114}$

\section{Protumorigenic roles of NFKB}

The potential role of NFKB in oncogenesis was confirmed in the discovery of the retroviral oncogene $v$-Rel, the homologue of the gene encoding cRel, one of the NFкB

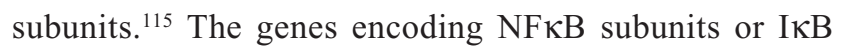
proteins are mutated in a variety of malignancies. Mutations and gene fusions of $I K K A$, which leads to the activation of IKK $\alpha$, were detected in breast cancer, where the activation of IKK $\alpha$ can maintain the self-renewal of breast cancer progenitors and has been shown to be responsible for the tumor-promoting effects of progesterone in breast cancer. ${ }^{116}$ However, the number of tumors with persistently activated nuclear NFKB is much larger than the subfraction of malignancies with confirmed mutations in NF $\kappa$ B or I $\kappa$ B-encoding genes. ${ }^{105}$ In breast cancer, colon cancer, and lymphatic cancer, the persistent activation of the NFKB-signaling pathway leads to abnormal cell proliferation and differentiation, enhanced metastasis, and treatment resistance. ${ }^{102,117,118}$ In colitis-associated colon cancer, positive effects of $\mathrm{NF \kappa B}$ have been shown by conditional silencing of IKK $\beta$, which persistently activates NFKB in intestinal epithelial cells. ${ }^{119}$ Recent studies have found that the Epstein-Barr virus (EBV) in several T- and NK-cell neoplasms can persistently activate $\mathrm{NF} \kappa \mathrm{B}$ via the viral protein LMP1, resembling the proteins in the TNF-receptor superfamily that induce NF $\kappa B$ activation through interaction with TRAF and TRADD, ${ }^{120,121}$ and contribute to development of EBV-positive T- and NKcell neoplasms. ${ }^{122}$

Mutations in upstream NFאB effectors in tumor cells will also result in the activation of the NFкB pathway, and then the persistent activation of $\mathrm{NF} \kappa \mathrm{B}$ can specifically target the promoters of oncogenes to form a positive-feedback loop. For instance, BRCA1 silencing in breast cancer cell lines induces phosphorylation of the Ser536 site of p65 and processing of $\mathrm{p} 100 / \mathrm{p} 52$, causing constitutive activation of the

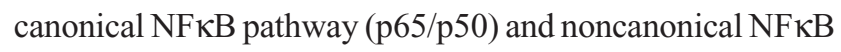
pathway (p100/p52) and promoting the nuclear translocation and accumulation of p52/RelB, which can enhance proliferation of MCF1 cells. ${ }^{102}$ In glioma stem cells, MLK4 binds to and phosphorylates the $\mathrm{NF} \kappa \mathrm{B}$ regulator IKK $\alpha$, leading to enhancement of the ability of NFאB binding to DNA and activation of $\mathrm{NF} \kappa \mathrm{B}$, which can induce mesenchymal trans-differentiation and radioresistance. ${ }^{123}$ Similarly, the activation of $\mathrm{mTORC} 1$ induced by LMP1 is a key regulator of the NFKB pathway in NPC cells. ${ }^{124}$ With knockdown of the MTORC1 gene, activation of NFKB induced by LMP1 and the transcription of Glut1 are markedly inhibited, negatively affecting the aerobic glycolysis in nasopharyngeal carcinoma cell HONE1. Therefore, the activation of NFאB pathway plays an important role in regulating the energy metabolism of nasopharyngeal carcinoma cells.

\section{Antitumorigenic roles of NFKB}

The role of NFKB in cancer is not always positive. Researchers have found that blockade of $\mathrm{NF} \kappa \mathrm{B}$ via overexpression of $\mathrm{I} \kappa \mathrm{B} \alpha$ promoted oncogenic Ras-induced invasive epidermal growth, resembling squamous-cell carcinoma. ${ }^{125}$ The overexpression of I $\mathrm{KB} \alpha$ induced by ablation of IKK $\beta$ can enhance the stability of $\mathrm{I} \kappa \mathrm{B}$ by inhibition of the phosphorylated $\mathrm{I} \kappa \mathrm{B} \alpha$ protein, resulting in inactivation of canonical $\mathrm{NF} \kappa \mathrm{B}$. In addition, the high expression of IKK $\beta$ that activates classical and nonclassical NFKB can suppress the progression of hepatocellular carcinoma by preventing DEN-induced cell death. ${ }^{126}$ Meanwhile, ablation of IKK $\beta$ can enhance the activation of JNK family members, including JNK1, which contributes to hepatocellular carcinoma development. ${ }^{127}$ Functional cross-talk between Nrf2 and NFאB/RelA protects the liver from necrosis, inflammation, and fibrosis, and thus prevents development of hepatocellular adenoma. ${ }^{128}$ Transcription factors Nrf2 and NF $\kappa B$ regulate the cellular antioxidant defense system, which is important in cell survival. ${ }^{129}$ Recently, researchers found that LCN2 is a upstream regulatory gene of the NFKB-Snail pathway and can inhibit the phosphorylation of p65 (p-p65) and the nuclear accumulation of p-p65 and Snail to inhibit activation of the NF $\kappa$ B pathway, thereby inhibiting colorectal cancer cell epithelial-mesenchymal transition and metastasis induced by the NFKB-Snail pathway. ${ }^{130}$ However, a number of studies have suggested that the NFKB pathway may upregulate the expression of LCN2 to promote the development of many cancers. ${ }^{131,132}$ Therefore, the NFKB pathway is diversified in different tumor cells, ${ }^{133,134}$ and the complex anticancer mechanism of the NFKB pathway is still not clear. Further study is warranted.

\section{Prospects of NFkB inhibitors}

It is unquestionable that $\mathrm{NF} \kappa \mathrm{B}$ inhibition as a means of cancer treatment has to be prioritized. Hundreds of NFKB inhibitors have been developed. ${ }^{135}$ These inhibitors are mainly designed 
to target one of four key points in the NFאB pathway: IKKs, NFкB-subunit dimers, proteasome $26 \mathrm{~S}$ in the case of proteasome inhibitors, and the Ub-ligase complex in the case of ubiquitination blockers. ${ }^{135}$ These four elements are essential to activation of the NFKB pathway. Moreover, natural products, antioxidants, nonsteroidal anti-inflammatory drugs, and glucocorticoids are capable of interfering with the NFKBsignaling cascade. ${ }^{136}$ As the phosphorylation step of $\mathrm{I} \kappa \mathrm{B} \alpha$ is a common reaction for the NF $\kappa B$ signaling induced by diverse stimuli, IKK inhibitors are considered an interesting approach

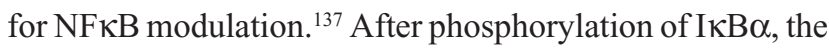
polyubiquitination and proteasomal degradation of the I $\mathrm{KB} \alpha$ protein will result in NFKB release for translocation to the nucleus. Therefore, ubiquitination blockers and proteasome inhibitors could also be considered as interesting modulators of the NFKB cascade. ${ }^{138}$

Many NFאB inhibitors have demonstrated appreciable anticancer activity in preclinical approaches. For example, BAY11-7082 can specifically abolish the binding of p65 to targeted DNA and downregulate the expression of TNF $\alpha .{ }^{139}$ As an IKK $\beta$ inhibitor, EF24 can block the NFKB-signaling pathway by inhibiting IKK $\beta$ phosphorylation, leading to cell-cycle arrest at the $\mathrm{G}_{2} / \mathrm{M}$ phase and apoptosis. ${ }^{140}$ The proteasome inhibitor MG132 inhibits tumor growth through downregulation of the NFKB-signaling pathway. ${ }^{141,142}$ In addition, T901 is a novel selective NFאB inhibitor functioning through binding to the NFKB complex in the cytosol, thus blocking its nuclear translocation and target-gene expression. ${ }^{143}$ Although many NFKB inhibitors have been developed to exert antitumor effects in a variety of experimental cancer models, ranging from lymphoma to solid tumors, no such drug has been clinically approved. ${ }^{144-146}$ Because the mechanism of the antitumor effect of NFkB inhibitors is not totally understood, many NFKB inhibitors are not effective as a single antitumor agent. ${ }^{147}$ The alterations of cellular signaling induced by NFKB inhibitors are generally involved in the establishment, evolution, and spread of malignant tumors. Therefore, considering the positive role of $\mathrm{NF} \kappa \mathrm{B}$ in the vast majority of cancer pathogenesis, $\mathrm{NF \kappa B}$ inhibitors that are able to modulate more than one therapeutic target related to this disease are currently considered the most promising alternatives to single anticancer drugs. ${ }^{148}$ Due to the wide range of possibilities to regulate the NFKB-signaling pathway, targeting different key points along the cascade offers a major opportunity. The challenge of NFKB inhibitors being applied in clinical intervention as novel anticancer-drug candidates lies in whether or not these NFKB inhibitors have better pharmacotherapeutic and safety profiles. Therefore, this approach still requires some improvements and more extensive studies to ensure and optimize the expected therapeutic benefit in the future. ${ }^{149}$

\section{Conclusion}

As a molecular hub linking inflammation and cancer, $\mathrm{NF} \kappa \mathrm{B}$ has been established as a crucial contributor in the development of malignant tumors. Although inhibition of $\mathrm{NF} \kappa \mathrm{B}$ activity is incapable of fully suppressing the growth of cancer, expression of $\mathrm{NF \kappa B}$ components and activated $\mathrm{NF} \kappa \mathrm{B}$ signaling still reflect a potentially serious risk of malignancies. ${ }^{150}$ Despite great progress in targeting NFкB signaling for cancer therapy, NFאB inhibitors have not been put into clinical application. Exploration of more effective and specific NFKB-targeted anticancer strategies is needed. With the development of technology, the inhibition of NF $\kappa B$ by a variety of inhibitors may pave the way for future personalized treatment strategies.

\section{Acknowledgments}

This work was supported in part by grants from the National Natural Science Foundation of China (81472595, 81402006) and the Research Project of the Health and Family Planning Commission of Hunan Province (B20180400, B20180582). LZX and SMT are first co-authors for this study.

\section{Author contributions}

LZX and SMT contributed to drafting and editing of the manuscript. DLC and QJL designed, revised, and finalized the manuscript. HRW and LDO participated in drafting and editing of the manuscript. YJZ participated in revision and coordination. JGL, YTT, and LL contributed to the literature search. MS and HW participated in conception and coordination. All authors contributed toward data analysis and drafting and revising the paper, and agree to be accountable for all aspects of the work.

\section{Disclosure}

The authors report no conflicts of interest in this work.

\section{References}

1. Yu AF, Ky B. Roadmap for biomarkers of cancer therapy cardiotoxicity. Heart. 2016;102(6):425-430.

2. Katada C, Yokoyama T, Yano T, et al. Alcohol consumption and multiple dysplastic lesions increase risk of squamous cell carcinoma in the esophagus, head, and neck. Gastroenterology. 2016;151(5):860.e7-869.e7.

3. Torre LA, Bray F, Siegel RL, Ferlay J, Lortet-Tieulent J, Jemal A. Global cancer statistics, 2012. CA Cancer J Clin. 2015;65(2):87-108.

4. Cao W, Kayama H, Chen ML, et al. The xenobiotic transporter Mdr1 enforces $\mathrm{T}$ cell homeostasis in the presence of intestinal bile acids. Immunity. 2017;47(6):1182.e10-1196.e10.

5. Chen H, Huang Q, Dong J, Lan Q. [Cancer initiating cell theory: popularity and controversies]. Ai Zheng. 2006;25(6):779-784. Chinese. 
6. Adjei AA, Hidalgo M. Intracellular signal transduction pathway proteins as targets for cancer therapy. J Clin Oncol. 2005;23(23):5386-5403.

7. Zhang W, Yin G, Dai J, et al. Chemoprevention by quercetin of oral squamous cell carcinoma by suppression of the NF- $\mathrm{kB}$ signaling pathway in DMBA-treated hamsters. Anticancer Res. 2017;37(8):4041-4049.

8. Sun Y, Fan X, Zhang Q, Shi X, Xu G, Zou C. Cancer-associated fibroblasts secrete FGF-1 to promote ovarian proliferation, migration, and invasion through the activation of FGF-1/FGFR4 signaling. Tumour Biol. 2017;39(7):1010428317712592.

9. Baud V, Karin M. Is NF- $\mathrm{kB}$ a good target for cancer therapy? Hopes and pitfalls. Nat Rev Drug Discov. 2009;8(1):33-40.

10. Kim JS, Kim EJ, Kim HS, Kurie JM, Ahn YH. MKK4 activates noncanonical NFKB signaling by promoting NFKB2-p100 processing. Biochem Biophys Res Commun. 2017;491(2):337-342.

11. Xing Y, Wang X, Jameson SC, Hogquist KA. Late stages of T cell maturation in the thymus involve NF- $\mathrm{\kappa B}$ and tonic type I interferon signaling. Nat Immunol. 2016;17(5):565-573.

12. Li Y, Zhou QL, Sun W, et al. Non-canonical NF- $\mathrm{KB}$ signalling and ETS1/2 cooperatively drive C250T mutant TERT promoter activation. Nat Cell Biol. 2015;17(10):1327-1338.

13. Wang H, Zhu Y, Xu X, et al. Ctenopharyngodon idella NF- $\mathrm{KB}$ subunit p65 modulates the transcription of IкB $\alpha$ in CIK cells. Fish Shellfish Immunol. 2016;54:564-572.

14. Shen LQ, Xu X, Liang HP, Li SM. [Screening of polypeptides interacting with Rel homology domain of NF-kB p50 subunit]. Xi Bao Yu Fen Zi Mian Yi Xue Za Zhi. 2007;23(9):804-806. Chinese.

15. Merchant M, Morkotinis V, Hale A, White M, Moran C. Crocodylian nuclear factor אB. Comp Biochem Physiol B Biochem Mol Biol. 2017; 213:28-34.

16. Keogh CE, Scholz CC, Rodriguez J, Selfridge AC, von Kriegsheim A, Cummins EP. Carbon dioxide-dependent regulation of NF- $\mathrm{\kappa B}$ family members RelB and p100 gives molecular insight into $\mathrm{CO}_{2}$-dependent immune regulation. J Biol Chem. 2017;292(27):11561-11571.

17. Tong L, Yuan Y, Wu S. Therapeutic microRNAs targeting the NF- $\mathrm{KB}$ signaling circuits of cancers. Adv Drug Deliv Rev. 2015;81:1-15.

18. Isoda K, Roth S, Nusslein-Volhard C. The functional domains of the Drosophila morphogen dorsal: evidence from the analysis of mutants. Genes Dev. 1992;6(4):619-630.

19. Annunziata CM, Davis RE, Demchenko Y, et al. Frequent engagement of the classical and alternative NF- $\mathrm{\kappa B}$ pathways by diverse genetic abnormalities in multiple myeloma. Cancer Cell. 2007;12(2):115-130.

20. Sies H, Berndt C, Jones DP. Oxidative stress. Annu Rev Biochem. 2017; $86: 715-748$

21. Espinosa L, Bigas A, Mulero MC. Novel functions of chromatinbound $\mathrm{I} \kappa \mathrm{B} \alpha$ in oncogenic transformation. Br J Cancer. 2014;111(9): $1688-1692$

22. Paul M, Kemparaju K, Girish KS. Inhibition of constitutive NF-кB activity induces platelet apoptosis via ER stress. Biochem Biophys Res Commun. 2017;493(4):1471-1477.

23. Rao P, Hayden MS, Long M, et al. IKB $\beta$ acts to inhibit and activate gene expression during the inflammatory response. Nature. 2010;466(7310): $1115-1119$

24. Whiteside ST, Epinat JC, Rice NR, Israel A. IкB epsilon, a novel mem-

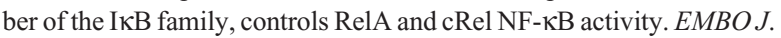
1997;16(6):1413-1426.

25. Thompson JE, Phillips RJ, Erdjument-Bromage H, Tempst P, Ghosh S. I $\kappa \mathrm{B}-\beta$ regulates the persistent response in a biphasic activation of NF-кB. Cell. 1995;80(4):573-582.

26. Durand JK, Baldwin AS. Targeting IKK and NF-KB for therapy. Adv Protein Chem Struct Biol. 2017;107:77-115.

27. Tao Z, Fusco A, Huang DB, et al. p100/IкB $\delta$ sequesters and inhibits NF- $\kappa B$ through $\kappa B$ some formation. Proc Natl Acad Sci U S A. 2014; 111(45):15946-15951.

28. Karin M. Nuclear factor- $\mathrm{\kappa B}$ in cancer development and progression. Nature. 2006;441(7092):431-436.

29. Xiao G, Rabson AB, Young W, Qing G, Qu Z. Alternative pathways of NF- $\kappa B$ activation: a double-edged sword in health and disease. Cytokine Growth Factor Rev. 2006;17(4):281-293.
30. Marienfeld RB, Palkowitsch L, Ghosh S. Dimerization of the IкB kinase-binding domain of NEMO is required for tumor necrosis

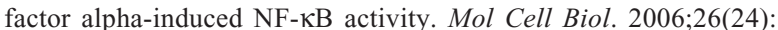
9209-9219.

31. DiDonato JA, Hayakawa M, Rothwarf DM, Zandi E, Karin M. A cytokine-responsive I $\mathrm{B}$ kinase that activates the transcription factor NF-кB. Nature. 1997;388(6642):548-554.

32. Annemann M, Plaza-Sirvent C, Schuster M, et al. Atypical IкB proteins in immune cell differentiation and function. Immunol Lett. 2016; $171: 26-35$

33. Sivanandan S, Naganathan AN. A disorder-induced domino-like destabilization mechanism governs the folding and functional dynamics of the repeat protein IKB $\alpha$. PLoS Comput Biol. 2013;9(12):e1003403.

34. Roth S, Rottach A, Lotz-Havla AS, et al. Rad50-CARD9 interactions link cytosolic DNA sensing to IL-1 $\beta$ production. Nat Immunol. 2014; 15(6):538-545.

35. Schneider AT, Gautheron J, Feoktistova M, et al. RIPK1 suppresses a TRAF2-dependent pathway to liver cancer. Cancer Cell. 2017;31(1): 94-109.

36. Kelly PN, Romero DL, Yang Y, et al. Selective interleukin-1 receptorassociated kinase 4 inhibitors for the treatment of autoimmune disorders and lymphoid malignancy. J Exp Med. 2015;212(13):2189-2201.

37. Abdul-Sater AA, Edilova MI, Clouthier DL, Mbanwi A, Kremmer E, Watts TH. The signaling adaptor TRAF1 negatively regulates Tolllike receptor signaling and this underlies its role in rheumatic disease. Nat Immunol. 2017;18(1):26-35.

38. Kinpara $\mathrm{S}$, Ito $\mathrm{S}$, Takahata $\mathrm{T}$, et al. Involvement of double-stranded RNA-dependent protein kinase and antisense viral RNA in the constitutive NFKB activation in adult T-cell leukemia/lymphoma cells. Leukemia. 2015;29(6):1425-1429.

39. He H, Chang R, Zhang T, Yang C, Kong Z. ATM mediates DAB2IPdeficient bladder cancer cell resistance to ionizing radiation through the p38MAPK and NF-אB signaling pathway. Mol Med Rep. 2017;16(2): 1216-1222.

40. Pak C, Miyamoto S. A new alpha in line between KRAS and NF-kB activation? Cancer Discov. 2013;3(6):613-615.

41. Baeuerle PA, Baltimore D. Activation of DNA-binding activity in an apparently cytoplasmic precursor of the NF- $\mathrm{KB}$ transcription factor. Cell. 1988;53(2):211-217.

42. Brady G, Haas DA, Farrell PJ, Pichlmair A, Bowie AG. Molluscum contagiosum virus protein $\mathrm{MC} 005$ inhibits NF- $\mathrm{\kappa B}$ activation by targeting NEMO-regulated IкB kinase activation. $J$ Virol. 2017;91(15): e00545.

43. Briggs LC, Chan AW, Davis CA, et al. IKK $\gamma$-mimetic peptides block the resistance to apoptosis associated with Kaposi's sarcoma-associated herpesvirus infection. $J$ Virol. 2017;91(23):e01170.

44. Wu YH, Huang YF, Chang TH, Chou CY. Activation of TWIST1 by COL11A1 promotes chemoresistance and inhibits apoptosis in ovarian cancer cells by modulating NF- $\mathrm{KB}$-mediated IKK $\beta$ expression. Int $J$ Cancer. 2017;141(11):2305-2317.

45. Petersheim D, Massaad MJ, Lee S, et al. Mechanisms of genotypephenotype correlation in autosomal dominant anhidrotic ectodermal dysplasia with immune deficiency. J Allergy Clin Immunol. Epub 2017 Jun 17.

46. Pujari R, Hunte R, Thomas R, et al. Human T-cell leukemia virus type 1 (HTLV-1) tax requires CADM1/TSLC1 for inactivation of the

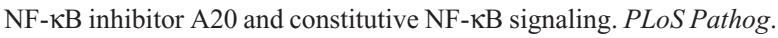
2015;11(3):e1004721

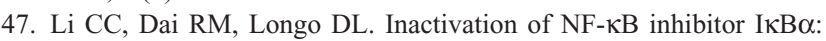
ubiquitin-dependent proteolysis and its degradation product. Biochem Biophys Res Commun. 1995;215(1):292-301.

48. Geng Z, Wei L, Zhang C, Yan X. Astragalus polysaccharide a component of traditional Chinese medicine inhibits muscle cell atrophy (cachexia) in an in vivo and in vitro rat model of chronic renal failure by activating the ubiquitin-proteasome pathway. Exp Ther Med. 2017; 14(1):91-96.

49. Chen ZJ. Ubiquitination in signaling to and activation of IKK. Immunol Rev. 2012;246(1):95-106. 
50. Sunami Y, Ringelhan M, Kokai E, et al. Canonical NF- $\kappa B$ signaling in hepatocytes acts as a tumor-suppressor in hepatitis B virus surface antigen-driven hepatocellular carcinoma by controlling the unfolded protein response. Hepatology. 2016;63(5):1592-1607.

51. Dejardin E. The alternative NF- $\mathrm{BB}$ pathway from biochemistry to biology: pitfalls and promises for future drug development. Biochem Pharmacol. 2006;72(9):1161-1179.

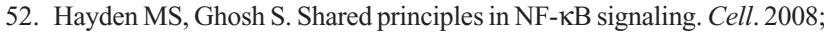
132(3):344-362.

53. Cildir G, Low KC, Tergaonkar V. Noncanonical NF- $\kappa \mathrm{B}$ signaling in health and disease. Trends Mol Med. 2016;22(5):414-429.

54. Sun SC. Non-canonical NF-אB signaling pathway. Cell Res. 2011;21(1): 71-85.

55. Sun SC. The noncanonical NF-кB pathway. Immunol Rev. 2012;246(1): 125-140.

56. Almaden JV, Liu YC, Yang E, et al. B-cell survival and development controlled by the coordination of NF- $\kappa \mathrm{B}$ family members RelB and cRel. Blood. 2016;127(10):1276-1286.

57. Willmann KL, Sacco R, Martins R, et al. Expanding the interactome of the noncanonical NF-кB signaling pathway. JProteome Res. 2016;15(9): 2900-2909.

58. Al-Sadi R, Guo S, Ye D, Rawat M, Ma TY. TNF- $\alpha$ modulation of intestinal tight junction permeability is mediated by NIK/IKK- $\alpha$ axis

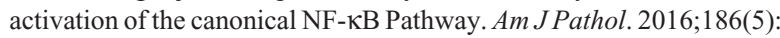
1151-1165.

59. Ho SC, Wu SM, Feng PH, et al. Noncanonical NF- $\mathrm{BB}$ mediates the suppressive effect of neutrophil elastase on IL-8/CXCL8 by inducing NKRF in human airway smooth muscle. Sci Rep. 2017;7:44930.

60. Hu H, Brittain GC, Chang JH, et al. OTUD7B controls non-canonical NF- $\kappa \mathrm{B}$ activation through deubiquitination of TRAF3. Nature. 2013; 494(7437):371-374.

61. Sundaram GM, Bramhachari PV. Molecular interplay of pro-inflammatory transcription factors and non-coding RNAs in esophageal squamous cell carcinoma. Tumour Biol. 2017;39(6):1010428317705760.

62. Gilmore TD. Introduction to NF- $\kappa \mathrm{B}$ : players pathways perspectives. Oncogene. 2006;25(51):6680-6684.

63. Moles A, Butterworth JA, Sanchez A, et al. A RelA(p65) Thr505 phospho-site mutation reveals an important mechanism regulating NF-אB-dependent liver regeneration and cancer. Oncogene. 2016;35(35) 4623-4632.

64. Delcourt V, Franck J, Leblanc E, et al. Combined mass spectrometry imaging and top-down microproteomics reveals evidence of a hidden proteome in ovarian cancer. EBioMedicine. 2017;21:55-64.

65. Richard SA, Jiang Y, Xiang LH, et al. Post-translational modifications of high mobility group box 1 and cancer. Am J Transl Res. 2017;9(12): 5181-5196.

66. Hirata Y, Takahashi M, Morishita T, Noguchi T, Matsuzawa A. Posttranslational modifications of the TAK1-TAB complex. Int J Mol Sci. 2017;18(1):E205.

67. Viatour P, Merville MP, Bours V, Chariot A. Phosphorylation of NF- $\kappa$ B and $\mathrm{I} \kappa \mathrm{B}$ proteins: implications in cancer and inflammation. Trends Biochem Sci. 2005;30(1):43-52.

68. O'Shea JM, Perkins ND. Regulation of the RelA (p65) transactivation domain. Biochem Soc Trans. 2008;36(Pt 4):603-608.

69. Perkins ND. Post-translational modifications regulating the activity and function of the nuclear factor $\kappa \mathrm{B}$ pathway. Oncogene. 2006;25(51): 6717-6730.

70. Won M, Byun HS, Park KA, Hur GM. Post-translational control of

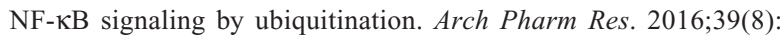
1075-1084.

71. Wang YC, Peterson SE, Loring JF. Protein post-translational modifications and regulation of pluripotency in human stem cells. Cell Res. 2014;24(2):143-160.

72. Pickart CM. Back to the future with ubiquitin. Cell. 2004;116(2): 181-190.

73. Rieser E, Cordier SM, Walczak H. Linear ubiquitination: a newly discovered regulator of cell signalling. Trends Biochem Sci. 2013;38(2): 94-102.
74. Elliott PR, Leske D, Hrdinka M, et al. SPATA2 links CYLD to LUBAC, activates CYLD, and controls LUBAC signaling. Mol Cell. 2016;63(6): 990-1005.

75. Fiil BK, Gyrd-Hansen M. Met1-linked ubiquitination in immune signalling. FEBS J. 2014;281(19):4337-4350.

76. Zhong X, Lee HN, Surh YJ. RvD1 inhibits TNF $\alpha$-induced c-Myc expression in normal intestinal epithelial cells and destabilizes hyperexpressed c-Myc in colon cancer cells. Biochem Biophys Res Commun. 2018;496(2):316-323

77. Ghosh S, Dass JF. Study of pathway cross-talk interactions with NF-кB leading to its activation via ubiquitination or phosphorylation: a brief review. Gene. 2016;584(1):97-109.

78. Zeng KW, Liao LX, Lv HN, et al. Natural small molecule FMHM inhibits lipopolysaccharide-induced inflammatory response by promoting TRAF6 degradation via K48-linked polyubiquitination. Sci Rep. 2015;5:14715

79. Wang Y, Zhao W, Gao Q, et al. pVHL mediates K63-linked ubiquitination of IKK $\beta$ leading to IKK $\beta$ inactivation. Cancer Lett. 2016; 383(1):1-8.

80. Jiang $X$, Chen ZJ. The role of ubiquitylation in immune defence and pathogen evasion. Nat Rev Immunol. 2011;12(1):35-48.

81. Lu X, Yarbrough WG. Negative regulation of RelA phosphorylation: emerging players and their roles in cancer. Cytokine Growth Factor Rev. 2015;26(1):7-13

82. Afonina IS, Zhong Z, Karin M, Beyaert R. Limiting inflammation: the negative regulation of NF- $\kappa \mathrm{B}$ and the NLRP3 inflammasome. Nat Immunol. 2017;18(8):861-869.

83. Ren L, Li Z, Dai C, et al. Chrysophanol inhibits proliferation and induces apoptosis through NF- $\mathrm{KB} /$ cyclin D1 and NF- $\mathrm{KB} / \mathrm{Bcl}-2$ signaling cascade in breast cancer cell lines. Mol Med Rep. 2018;17(3):4376-4382.

84. Wang Y, Qin X, Zhu X, Chen W, Zhang J, Chen W. Oral cancer-derived exosomal NAP1 enhances cytotoxicity of natural killer cells via the IRF-3 pathway. Oral Oncol. 2018;76:34-41.

85. Zhong H, Voll RE, Ghosh S. Phosphorylation of NF- $\kappa$ B p 65 by PKA stimulates transcriptional activity by promoting a novel bivalent interaction with the coactivator CBP/p300. Mol Cell. 1998;1(5):661-671.

86. Liu Y, Mayo MW, Nagji AS, et al. Phosphorylation of RelA/p65 promotes DNMT-1 recruitment to chromatin and represses transcription of the tumor metastasis suppressor gene BRMS1. Oncogene. 2012; 31(9):1143-1154

87. Gunster RA, Matthews SA, Holden DW, Thurston TL. SseK1 and SseK3 type III secretion system effectors inhibit NF- $\kappa$ B signaling and necroptotic cell death in Salmonella-infected macrophages. Infect Immun. 2017;85(3):e00010.

88. Wang H, Cebotaru L, Lee HW, et al. CFTR controls the activity of NF- $\kappa$ B by enhancing the degradation of TRADD. Cell Physiol Biochem. 2016;40(5):1063-1078.

89. Lv F, Huang Y, Lv W, et al. MicroRNA-146a Ameliorates inflammation via TRAF6/NF- $\mathrm{KB}$ pathway in intervertebral disc cells. Med Sci Monit. 2017;23:659-664.

90. Sun J, Yu X, Wang C, et al. RIP-1/c-FLIPL induce hepatic cancer cell apoptosis through regulating tumor necrosis factor-related apoptosisinducing ligand (TRAIL). Med Sci Monit. 2017;23:1190-1199.

91. Chirieleison SM, Kertesy SB, Abbott DW. Synthetic biology reveals the uniqueness of the RIP kinase domain. J Immunol. 2016;196(10): 4291-4297.

92. Richardson JS, Aminudin N, Malek SN. Chalepin: a compound from Ruta angustifolia $\mathrm{L}$. pers exhibits cell cycle arrest at $\mathrm{S}$ phase suppresses nuclear factor-K B (NF- $\mathrm{B}$ ) pathway signal transducer and activation of transcription 3 (STAT3) phosphorylation and extrinsic apoptotic pathway in non-small cell lung cancer carcinoma (A549). Pharmacogn Mag. 2017;13(51):489-498.

93. Lu T, Stark GR. NF-кB: regulation by methylation. Cancer Res. 2015; 75(18):3692-3695.

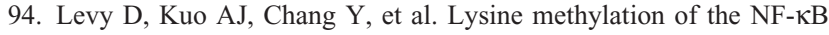
subunit RelA by SETD6 couples activity of the histone methyltransferase GLP at chromatin to tonic repression of NF- $\mathrm{\kappa B}$ signaling. Nat Immunol. 2011;12(1):29-36. 
95. Ea CK, Baltimore D. Regulation of NF- $\mathrm{KB}$ activity through lysine monomethylation of p65. Proc Natl Acad Sci U S A. 2009;106(45): 18972-18977.

96. Lu T, Yang M, Huang DB, et al. Role of lysine methylation of NF- $\mathrm{KB}$ in differential gene regulation. Proc Natl Acad Sci U S A. 2013;110(33): 13510-13515.

97. Song W, Mazzieri R, Yang T, Gobe GC. Translational significance for tumor metastasis of tumor-associated macrophages and epithelialmesenchymal transition. Front Immunol. 2017;8:1106.

98. Zhong L, Chen XF, Wang T, et al. Soluble TREM2 induces inflammatory responses and enhances microglial survival. J Exp Med. 2017;214(3): 597-607.

99. Vlantis K, Wullaert A, Polykratis A, et al. NEMO prevents RIP kinase 1mediated epithelial cell death and chronic intestinal inflammation by NF-אB-dependent and -independent functions. Immunity. 2016; 44(3):553-567.

100. Tosello V, Bordin F, Yu J, et al. Calcineurin and GSK-3 inhibition sensitizes T-cell acute lymphoblastic leukemia cells to apoptosis through X-linked inhibitor of apoptosis protein degradation. Leukemia. 2016;30(4):812-822.

101. Kwon HJ, Choi GE, Ryu S, et al. Stepwise phosphorylation of p65 promotes NF- $\mathrm{\kappa B}$ activation and NK cell responses during target cell recognition. Nat Commun. 2016;7:11686.

102. Sau A, Lau R, Cabrita MA, et al. Persistent activation of NF- $k B$ in BRCA1-deficient mammary progenitors drives aberrant proliferation and accumulation of DNA damage. Cell Stem Cell. 2016;19(1):52-65.

103. Salazar L, Kashiwada T, Krejci P, et al. Fibroblast growth factor receptor 3 interacts with and activates TGF $\beta$-activated kinase 1 tyrosine phosphorylation and NFKB signaling in multiple myeloma and bladder cancer. PLoS One. 2014;9(1):e86470.

104. Liu F, Bardhan K, Yang D, et al. NF-kB directly regulates Fas transcription to modulate Fas-mediated apoptosis and tumor suppression. J Biol Chem. 2012;287(30):25530-25540.

105. Ben-Neriah Y, Karin M. Inflammation meets cancer with NF- $\mathrm{KB}$ as the matchmaker. Nat Immunol. 2011;12(8):715-723.

106. Grivennikov SI, Greten FR, Karin M. Immunity inflammation and cancer. Cell. 2010;140(6):883-899.

107. Smale ST. Hierarchies of NF-אB target-gene regulation. Nat Immunol. 2011;12(8):689-694.

108. Kiechl S, Wittmann J, Giaccari A, et al. Blockade of receptor activator of nuclear factor- $\mathrm{KB}$ (RANKL) signaling improves hepatic insulin resistance and prevents development of diabetes mellitus. Nat Med. 2013;19(3):358-363.

109. Kondegowda NG, Fenutria R, Pollack IR, et al. Osteoprotegerin and denosumab stimulate human beta cell proliferation through inhibition of the receptor activator of NF-KB ligand pathway. Cell Metab. 2015;22(1):77-85.

110. Zanotto-Filho A, Gonçalves RM, Klafke K, et al. Inflammatory landscape of human brain tumors reveals an NFKB dependent cytokine pathway associated with mesenchymal glioblastoma. Cancer Lett. 2017;390:176-187.

111. Son DS, Kabir SM, Dong Y, Lee E, Adunyah SE. Characteristics of chemokine signatures elicited by EGF and TNF in ovarian cancer cells. J Inflamm (Lond). 2013;10(1):25.

112. Olson TS, Ley K. Chemokines and chemokine receptors in leukocyte trafficking. Am J Physiol Regul Integr Comp Physiol. 2002;283(1): R7-R28.

113. Banerjee S, McGee DW. ROCK activity affects IL-1-induced signaling possibly through MKK4 and $\mathrm{p} 38 \mathrm{MAPK}$ in Caco-2 cells. In Vitro Cell Dev Biol Anim. 2016;52(8):878-884.

114. Greten FR, Arkan MC, Bollrath J, et al. NF- $\kappa B$ is a negative regulator of IL-1 $\beta$ secretion as revealed by genetic and pharmacological inhibition of IKK $\beta$. Cell. 2007;130(5):918-931.

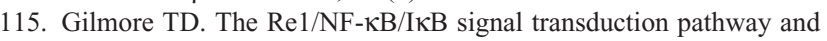
cancer. Cancer Treat Res. 2003;115:241-265.

116. Stratton MR, Campbell PJ, Futreal PA. The cancer genome. Nature. 2009;458(7239):719-724.
117. Forlani G, Abdallah R, Accolla RS, Tosi G. The major histocompatibility complex class II transactivator CIITA inhibits the persistent activation of NF- $\mathrm{KB}$ by the human $\mathrm{T}$ cell lymphotropic virus type 1 Tax-1 Oncoprotein. J Virol. 2016;90(7):3708-3721.

118. Walther W, Kobelt D, Bauer L, Aumann J, Stein U. Chemosensitization by diverging modulation by short-term and long-term TNF- $\alpha$ action on $\mathrm{ABCB} 1$ expression and $\mathrm{NF}-\mathrm{\kappa B}$ signaling in colon cancer. Int J Oncol. 2015;47(6):2276-2285.

119. Greten FR, Eckmann L, Greten TF, et al. IKK $\beta$ links inflammation and tumorigenesis in a mouse model of colitis-associated cancer. Cell. 2004;118(3):285-296.

120. Kieser A. Pursuing different "TRADDes": TRADD signaling induced by TNF-receptor 1 and the Epstein-Barr virus oncoprotein LMP1. Biol Chem. 2008;389(10):1261-1271.

121. Luftig M, Yasui T, Soni V, et al. Epstein-Barr virus latent infection membrane protein 1 TRAF-binding site induces NIK/IKK $\alpha$-dependent noncanonical NF-אB activation. Proc Natl Acad Sci US A. 2004;101(1):141-146.

122. Takada $\mathrm{H}$, Imadome KI, Shibayama $\mathrm{H}$, et al. EBV induces persistent NF- $\mathrm{KB}$ activation and contributes to survival of EBV-positive neoplastic T- or NK-cells. PLoS One. 2017;12(3):e0174136.

123. Kim SH, Ezhilarasan R, Phillips E, et al. Serine/threonine kinase MLK4 determines mesenchymal identity in glioma stem cells in an NF-KB-dependent manner. Cancer Cell. 2016;29(2):201-213.

124. Zhang J, Jia L, Lin W, et al. Epstein-Barr virus-encoded latent membrane protein 1 upregulates glucose transporter 1 transcription via the mTORC1/NF-кB signaling pathways. J Virol. 2017;91(6):e02168.

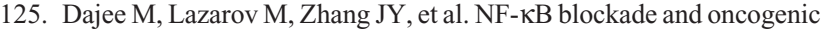
Ras trigger invasive human epidermal neoplasia. Nature. 2003; 421(6923):639-643.

126. Luedde T, Beraza N, Kotsikoris V, et al. Deletion of NEMO/IKK $\gamma$ in liver parenchymal cells causes steatohepatitis and hepatocellular carcinoma. Cancer Cell. 2007;11(2):119-132.

127. Sakurai T, He G, Matsuzawa A, et al. Hepatocyte necrosis induced by oxidative stress and IL- $1 \alpha$ release mediate carcinogen-induced compensatory proliferation and liver tumorigenesis. Cancer Cell. 2008; 14(2):156-165.

128. Kohler UA, Böhm F, Rolfs F, et al. NF- $\mathrm{kB} /$ RelA and Nrf2 cooperate to maintain hepatocyte integrity and to prevent development of hepatocellular adenoma. $J$ Hepatol. 2016;64(1):94-102.

129. Schreck R, Rieber P, Baeuerle PA. Reactive oxygen intermediates as apparently widely used messengers in the activation of the NF- $\mathrm{KB}$ transcription factor and HIV-1. EMBO J. 1991;10(8):2247-2258.

130. Feng M, Feng J, Chen W, et al. Lipocalin 2 suppresses metastasis of colorectal cancer by attenuating NF- $\mathrm{kB}-$ dependent activation of snail and epithelial mesenchymal transition. Mol Cancer. 2016;15(1):77.

131. Kaur S, Sharma N, Krishn SR, et al. MUC4-mediated regulation of acute phase protein lipocalin 2 through HER2/AKT/NF- $\mathrm{\kappa B}$ signaling in pancreatic cancer. Clin Cancer Res. 2014;20(3):688-700.

132. Mahadevan NR, Rodvold J, Almanza G, Perez AF, Wheeler MC, Zanetti M. ER stress drives lipocalin 2 upregulation in prostate cancer cells in an NF-KB-dependent manner. BMC Cancer. 2011;11:229.

133. Shi Z, Hu Z, Chen D, et al. MicroRNA-200a mediates nasopharyngeal carcinoma cell proliferation through the activation of nuclear factor-кB. Mol Med Rep. 2016;13(2):1732-1738.

134. Wang Y, Ren F, Wang Y, et al. CHIP/Stub1 functions as a tumor suppressor and represses NF- $\mathrm{\kappa B}$-mediated signaling in colorectal cancer. Carcinogenesis. 2014;35(5):983-991.

135. Erstad DJ, Cusack JC Jr. Targeting the NF- $\kappa B$ pathway in cancer therapy. Surg Oncol Clin N Am. 2013;22(4):705-746.

136. Gupta SC, Sundaram C, Reuter S, Aggarwal BB. Inhibiting NF- $\kappa B$ activation by small molecules as a therapeutic strategy. Biochim Biophys Acta. 2010;1799(10-12):775-787.

137. Castro AC, Dang LC, Soucy F, et al. Novel IKK inhibitors: $\beta$-carbolines. Bioorg Med Chem Lett. 2003;13(14):2419-2422.

138. Gilmore TD, Herscovitch M. Inhibitors of NF- $\mathrm{\kappa B}$ signaling:785 and counting. Oncogene. 2006;25(51):6887-6899. 
139. Wu CY, Ke Y, Zeng YF, Zhang YW, Yu HJ. Anticancer activity of Astragalus polysaccharide in human non-small cell lung cancer cells. Cancer Cell Int. 2017; 17:115.

140. Jin R, Chen Q, Yao S, et al. Synthesis and anti-tumor activity of EF24 analogues as IKK $\beta$ inhibitors. Eur J Med Chem. 2017;144:218-228.

141. Zhang Y, Yang B, Zhao J, Li X, Zhang L, Zhai Z. Proteasome inhibitor carbobenzoxy-1-leucyl-1-leucyl-1-leucinal (MG132) enhances therapeutic effect of paclitaxel on breast cancer by inhibiting nuclear factor (NF)- $\kappa$ B signaling. Med Sci Monit. 2018;24:294-304.

142. Sun F, Zhang Y, Xu L, et al. Proteasome inhibitor MG132 enhances cisplatin-induced apoptosis in osteosarcoma cells and inhibits tumor growth. Oncol Res. Epub 2017 Nov 30.

143. Vaisitti T, Gaudino F, Ouk S, et al. Targeting metabolism and survival in chronic lymphocytic leukemia and Richter syndrome cells by a novel NF-кB inhibitor. Haematologica. 2017;102(11):1878-1889.

144. Vu KT, Zhang F, Hulleman JD. Conditional genetically encoded small molecule-regulated inhibition of NFKB signaling in RPE cells. Invest Ophthalmol Vis Sci. 2017;58(10):4126-4137.

145. Pollock N, Taylor G, Jobe F, Guzman E. Modulation of the transcription factor NF- $\mathrm{KB}$ in antigen-presenting cells by bovine respiratory syncytial virus small hydrophobic protein. J Gen Virol. 2017;98(7): $1587-1599$
146. Qian C, Chen X, Qi Y, et al. Sporamin induces apoptosis and inhibits NF- $\mathrm{KB}$ activation in human pancreatic cancer cells. Tumour Biol. 2017;39(7):1010428317706917.

147. Oida K, Matsuda A, Jung K, et al. Nuclear factor-kB plays a critical role in both intrinsic and acquired resistance against endocrine therapy in human breast cancer cells. Sci Rep. 2014;4:4057.

148. Chen F, Castranova V, Shi X. New insights into the role of nuclear factor- $\kappa \mathrm{B}$ in cell growth regulation. Am J Pathol. 2001;159(2): 387-397

149. Barbosa ML, da Conceicao RA, Fraga AG, et al. NF- $\kappa B$ signaling pathway inhibitors as anticancer drug candidates. Anticancer Agents Med Chem. 2017;17(4):483-490.

150. Capece D, Verzella D, Tessitore A, Alesse E, Capalbo C, Zazzeroni F. Cancer secretome and inflammation: the bright and the dark sides of NF-кB. Semin Cell Dev Biol. Epub 2017 Aug 2.

\section{Publish your work in this journal}

OncoTargets and Therapy is an international, peer-reviewed, open access journal focusing on the pathological basis of all cancers, potential targets for therapy and treatment protocols employed to improve the management of cancer patients. The journal also focuses on the impact of management programs and new therapeutic agents and protocols on

\section{Dovepress}

patient perspectives such as quality of life, adherence and satisfaction. The manuscript management system is completely online and includes a very quick and fair peer-review system, which is all easy to use. Visit http://www.dovepress.com/testimonials.php to read real quotes from published authors. 